\title{
Alternative and Legacy Perfluoroalkyl Substances: Differences between European and Chinese River/Estuary Systems
}

ARTICLE in ENVIRONMENTAL SCIENCE \& TECHNOLOGY · JUNE 2015

Impact Factor: $5.33 \cdot$ DOI: 10.1021/acs.est.5b01648 · Source: PubMed

CITATIONS

4

4 AUTHORS:

Franziska Heydebreck

Helmholtz-Zentrum Geesthacht

1 PUBLICATION 4 CITATIONS

SEE PROFILE

\section{Zhiyong Xie}

Helmholtz-Zentrum Geesthacht

77 PUBLICATIONS $\mathbf{1 , 8 4 2}$ CITATIONS

SEE PROFILE
READS

114
Jianhui Tang

Chinese Academy of Sciences

62 PUBLICATIONS 1,018 CITATIONS

SEE PROFILE

Ralf Ebinghaus

Helmholtz-Zentrum Geesthacht

228 PUBLICATIONS $\quad 6,695$ CITATIONS

SEE PROFILE 


\title{
Alternative and Legacy Perfluoroalkyl Substances: Differences between European and Chinese River/Estuary Systems
}

\author{
Franziska Heydebreck, ${ }^{\dagger, \ddagger}$ Jianhui Tang, ${ }^{*} \S$ Zhiyong Xie, $^{\dagger}$ and Ralf Ebinghaus ${ }^{\dagger}$ \\ ${ }^{\dagger}$ Department for Environmental Chemistry, Institute of Coastal Research, Helmholtz-Zentrum Geesthacht, Centre for Materials and \\ Coastal Research, Max-Planck-Strasse 1, 21502 Geesthacht, Schleswig-Holstein, Germany \\ ${ }^{\ddagger}$ Department of Chemistry, University of Hamburg, Martin-Luther-King-Platz 6, 20146 Hamburg, Hamburg, Germany \\ ${ }^{\S}$ Key Laboratory of Coastal Zone Environmental Processes and Ecological Remediation, Yantai Institute of Coastal Zone Research, \\ CAS, Yantai, Shandong 264003, PR China
}

\section{Supporting Information}

ABSTRACT: The production and use of long-chain perfluoroalkyl substances (PFASs) must comply with national and international regulations. Driven by increasingly stringent regulations, their production has been outsourced to less regulated countries in Asia. In addition, the fluoropolymer industry started to use fluorinated alternatives, such as 2,3,3,3tetrafluoro-2-(1,1,2,2,3,3,3-heptafluoropropoxy)propanoic acid (HFPO-DA). Between August 2013 and September 2014, we investigated the occurrence and distribution of HFPO-DA and legacy PFASs in surface waters of the following river/estuary systems: the Elbe and Rhine Rivers in Germany, the Rhine-

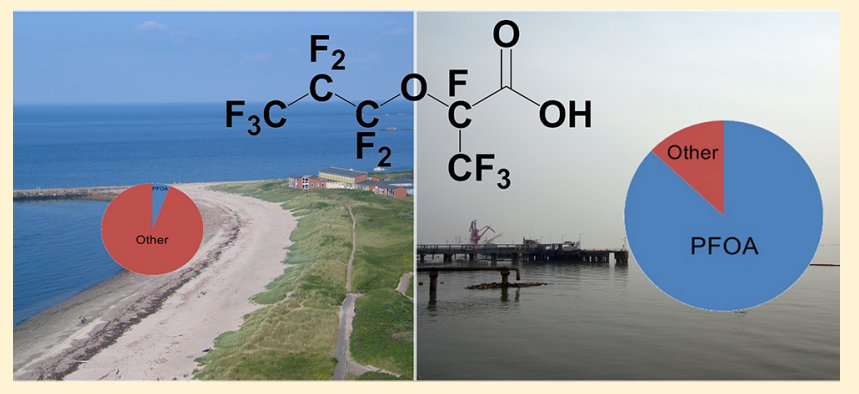
Meuse delta in The Netherlands, and the Xiaoqing River in China. Distinct differences were revealed among the study areas; notably, the Chinese samples were highly polluted by an industrial point source discharging mainly perfluorooctanoic acid (PFOA). This particular point source resulted in concentrations more than 6000 times higher than an industrial point source observed in the Scheur River, where HFPO-DA was the dominant compound with a concentration of $73.1 \mathrm{ng} / \mathrm{L}$. Moreover, HFPO-DA was detected in all samples along the coastline of the North Sea, indicating that the compound may be transported from the Rhine-Meuse delta into the German Bight via the water current. To the best of our knowledge, the fluorinated alternative, HFPO-DA, was detected for the first time in surface waters of Germany and China.

\section{INTRODUCTION}

Perfluoroalkyl substances (PFASs), chemicals of anthropogenic origin, have been the subject of research for nearly two decades. Based on their chemical structures, the substances are divided into long-chain PFASs ( $\geq$ seven carbon atoms) and short-chain PFASs (<seven carbon atoms). ${ }^{1}$ Long-chain PFASs are of great concern because they are highly persistent, bioaccumulative, toxic, and ubiquitous in the environment. ${ }^{2}$ Their production and use have been restricted to comply with national and international regulations. In 2009, perfluorooctanesulfonic acid (PFOS) and related substances based on perfluorooctane sulfonyl fluoride (POSF) were included in the Stockholm Convention, a global treaty designed to protect the environment and human health from persistent organic pollutants (POPs). ${ }^{3}$ Additionally, the long-chain $\mathrm{C}_{11}$ to $\mathrm{C}_{14}$ perfluoroalkyl carboxylic acids (PFCAs), as well as perfluorooctanoic acid (PFOA) and its salt ammonium pentadecafluorooctanoate (APFO), were listed in the Candidate List of substances of very high concern by the European Chemicals Agency. ${ }^{4}$ There has been, since October 2014, an ongoing proposal to ban the production, use, and placement on the market of PFOA, its salts, and PFOA-related substances in the European Union. ${ }^{5}$ As a consequence of these regulations, the production of long- chain PFASs has shifted toward less regulated countries in Asia as well as toward nonregulated short-chain PFASs. ${ }^{6,7}$ The shortchain PFASs, such as perfluorobutanesulfonic acid (PFBS), are allegedly less toxic and bioaccumulative than the long-chain PFASs, but they are still resistant to environmental degradation. ${ }^{8}$ Additionally, their solubility increases as the number of carbon atoms decreases, ${ }^{9}$ which makes the substances more mobile and problematic if contaminated surface water is used as a drinking water source. ${ }^{10}$ Furthermore, a higher amount of short-chain PFASs is necessary to achieve a comparative level of water and oil repellency. Thus, the fluoropolymer industry has attempted to develop fluorinated substances with more favorable toxicological and environmental attributes. ${ }^{11,12}$ Information on structural properties, production volumes, uses, and environmental and biological effects of those alternatives is limited. Some fluorinated alternatives have been identified recently including 2,3,3,3-tetrafluoro-2-(1,1,2,2,3,3,3heptafluoropropoxy)propanoic acid (HFPO-DA,

Received: April 1, 2015

Revised: June 18, 2015

Accepted: June 24, 2015 

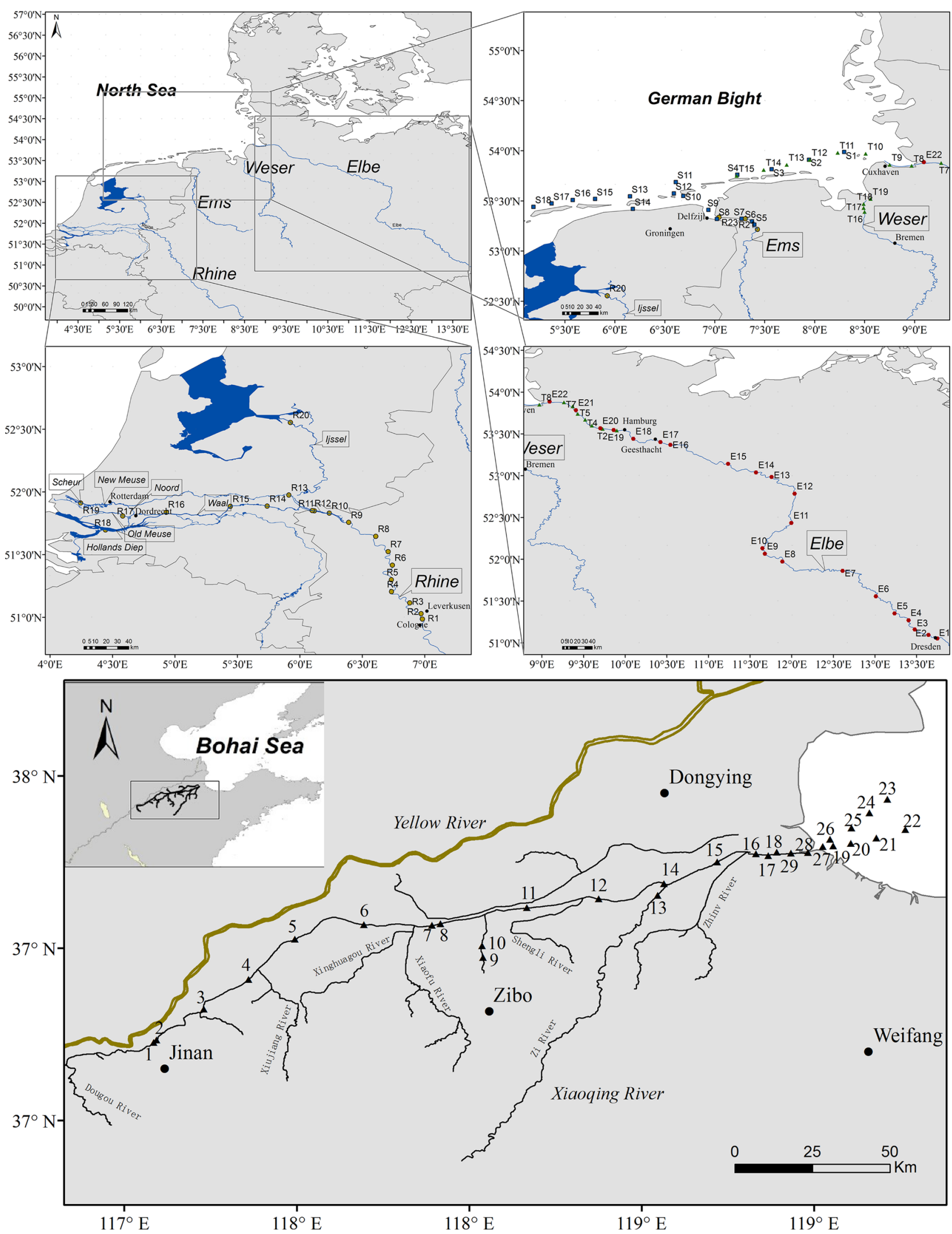

Figure 1. Overview of the sampling sites in The Netherlands and Germany (top) and in the People's Republic of China (bottom) (created with the help of Esri ArcGIS 10.2.1.3497 software).

$\left.\mathrm{C}_{6} \mathrm{HF}_{11} \mathrm{O}_{3}\right) \cdot{ }^{13,14}$ It is the dimer acid of hexafluoropropylene oxide (HFPO) that is used as a monomer or monomer precursor in the synthesis of organofluorine products. ${ }^{15}$ The chemical structure is characterized by a carboxylic group that is attached to a perfluoroether chain (Figure S1). The ammonium salt of HFPO-DA, namely GenX, is known as an APFO or 
PFOA alternative that has been produced as a processing aid for fluoropolymer resin manufacturing since $2010 .^{16}$ The substance has been registered under $\mathrm{REACH}$ - a regulation for the registration, evaluation, authorization, and restriction of chemicals in the European Union - with an annual production volume of 10 to 100 tons. $^{17}$ The producer developed an exposure control strategy to prevent the substance from spreading beyond the production site. ${ }^{16}$ However, GenX is chemically stable and would be persistent if released into the environment. $^{16,17}$ Thus, it is debatable whether this chemical is a suitable alternative for PFOA. Preliminary results have shown that HFPO-DA and other structurally similar compounds are present in river water downstream of a known historical fluorochemical manufacturer effluent in North Carolina, USA. ${ }^{13}$ Other fluorinated alternatives, such as ADONA and F-53B, have been detected in the $\mathrm{Alz}$ River ${ }^{18}$ or in wastewater from the chrome plating industry. ${ }^{19}$ However, for quantification of fluorinated alternatives in environmental samples, analytical standards are mandatory.

Within the scope of this study, HFPO-DA was the only available analytical standard. Thus, the purpose of our study was to investigate whether the fluorinated alternative HFPODA is present in riverine and coastal areas of Germany and China and, if so, to locate the sources of its release. By comparing the concentrations of HFPO-DA in the study areas with those of the predecessor substance PFOA and the shortchain PFASs, which were primarily used as alternatives, the differences in pollution levels and distribution patterns of PFASs between Germany and China should become apparent. In addition, a discussion regarding the possible causes behind the different results is warranted.

\section{MATERIALS AND METHODS}

Sampling Sites. The areas of study were the Lower Rhine River, including its branch streams Waal, Old Meuse, Hollands Diep, Scheur, and Ijssel; the Elbe River; the coastal region of the North Sea, including the estuaries of the Weser and Ems Rivers; and the Xiaoqing River, including Laizhou Bay in the province of Shandong, China (Figure 1). All sampling areas were located in industrialized regions. Major urban districts, such as Leverkusen, Hamburg, and Bremen in Germany, Rotterdam in The Netherlands, as well as Jinan, Zibo, and Dongying in China, are located in the river catchment areas. The Rhine River is Germany's longest river, at a total length of $1238 \mathrm{~km} .{ }^{20}$ It is an important waterway in Europe, connecting large industrial inland complexes with the port of Rotterdam, one of the biggest logistics hubs worldwide. The Rhine River splits downstream of the Dutch-German border forming the Rhine-Meuse delta before discharging into the North Sea. The Elbe River is the third largest river in Central Europe, with a length of approximately $1090 \mathrm{~km} .^{21}$ The population density is high along the German portion of the river, especially in the estuary - Hamburg had 2382 inhabitants $\mathrm{km}^{-2}$ in $2011^{22}-$ and numerous industrial activities are also located along the river. Both the Rhine and the Elbe catchment areas have a long history of industrialization and have been the seat of chemical, pharmaceutical, paper, and leather-processing industries since the 19th century. 21,23

In contrast, in the People's Republic of China, the industrial development has rapidly expanded over the past decade. The fast economic growth has led to an increasing demand for the production and use of PFASs and related chemicals. The Xiaoqing River is an artificial river channel that is $233 \mathrm{~km}$ long.
Once an important waterway, its use has been terminated due to decreased water flow and heavy pollution from domestic sewage and industrial wastewater. The Xiaoqing River receives wastewater from several major cities in which petrochemical, marine chemical, electronic, iron, and steel industries are located. It is, moreover, an important location for the fluoropolymer industry, with manufacturing sites for fluorinated refrigerants and polytetrafluoroethylene (PTFE) reaching production capacities from hundreds to thousands of tons per year. $^{24}$ The Xiaoqing River, thus, became one of the most polluted rivers in China, ${ }^{25}$ in which high PFOA levels of up to $76.9 \mathrm{ng} / \mathrm{g}$ in sediments ${ }^{26}$ and $4.5 \mu \mathrm{g} / \mathrm{L}$ in surface water ${ }^{24}$ were detected. The river discharges into Laizhou Bay, which is a part of the southern Bohai Sea and an important fishing region in North China.

Sample Collection. Five sampling campaigns were performed in Germany, The Netherlands, and the People's Republic of China between August 2013 and September 2014 (Figure 1 and Table S1). One liter of water samples was collected in polypropylene bottles (VWR International) or in polyethylene terephthalate bottles. The samples from the Rhine (August 2013) and Elbe (September 2014) Rivers were cooled during the sampling campaign and filtrated through glass fiber filters (GF/F, Whatman, $\varnothing 47 \mathrm{~mm}$ ) in the clean laboratory (class 10.000 according to US FED 209D) at the HelmholtzZentrum Geesthacht. All glass fiber filters were baked at $450{ }^{\circ} \mathrm{C}$ for $12 \mathrm{~h}$ before usage. The sampling campaigns in the coastal area of the North Sea (March and August 2014) were carried out on board the $R / V$ Ludwig Prandtl. The filtration of the samples from March 2014 was performed on board, and the samples from August 2014 were frozen to $-20{ }^{\circ} \mathrm{C}$ and filtrated in the clean laboratory. The samples from the Xiaoqing River (April 2014) were cooled during the sampling campaign and filtrated in the laboratory at the Yantai Institute for Coastal Zone Research. In total, 111 samples were analyzed for PFASs as described below.

Chemicals. The following substances were detected during the study: 2,3,3,3-tetrafluoro-2-(1,1,2,2,3,3,3,heptafluoropropoxy)propanoic acid (HFPO-DA), perfluorobutanoic acid (PFBA), perfluoropentanoic acid (PFPeA), perfluorohexanoic acid (PFHxA), perfluoroheptanoic acid (PFHpA), perfluorooctanoic acid (PFOA), perfluorononanoic acid (PFNA), perfluorodecanoic acid (PFDA), perfluoroundecanoic acid (PFUnDA), perfluorododecanoic acid (PFDoDA), perfluorobutanesulfonic acid (PFBS), perfluorohexanesulfonic acid (PFHxS), perfluorooctanesulfonic acid (PFOS), 3,3,4,4,5,5,6,6,7,7,8,8,8-tridecafluorooctane-1-sulfonic acid (6:2 FTS), 1,1,2,2,3,3,4,4,5,5,6,6,7,7,8,8,8-heptadecafluoro-1-octanesulfonamide (FOSA) (Table S2). All native and mass-labeled reference standards were purchased from Wellington Laboratories (Guelph, Canada). The following solvents and reagents were used for the sample treatment at Helmholtz-Zentrum Geesthacht, Germany: Methanol (Picograde) and acetone (Picograde) were purchased from LGC Standards (Wesel, Germany). Methanol (LiChroSolv) and ammonia solution 25\% (Suprapur) were purchased from Merck (Darmstadt, Germany). Ammonium acetate (LC-MS ultra) was purchased from Sigma-Aldrich (Steinheim, Germany). Millipore water was supplied by a Milli-Q Integral 5 (Darmstadt, Germany). In China, purified water was supplied by a Pall Cascada LS system. Methanol and acetone were purchased from Kermel (Tianjin, China) and from Sinopharm Chemical Reagent Co., Ltd. 
(Shanghai, China), respectively. Both solvents were distilled before usage.

Sample Extraction. The samples from the coastal area of the North Sea (August 2014) and the Rhine and Elbe Rivers were extracted in a clean laboratory. The samples from the Elbe estuary and German Bight (March 2014) were extracted on board the $R / V$ Ludwig Prandtl, while vacuum drying and elution were performed in the clean laboratory. The samples from the Xiaoqing River were extracted in the laboratory at the Yantai Institute for Coastal Zone Research. For sample extraction, glass funnels and solid phase extraction (SPE) cartridges (Waters Oasis Wax, $150 \mathrm{mg}, 6 \mathrm{~cm}^{3}, 30 \mu \mathrm{m}$ particle size) were used. Due to local conditions, the extraction was modified based on the method described by Ahrens et al. ${ }^{27}$ The SPE cartridges were cleaned with $10 \mathrm{~mL}$ of acetone, methanol, and $0.25 \%$ ammonium hydroxide in methanol, respectively. The samples were spiked with mass-labeled internal standards before extraction $(20 \mu \mathrm{L}, 250 \mathrm{pg} / \mu \mathrm{L})$. The cartridges were loaded with the samples at approximately $2 \mathrm{~mL} / \mathrm{min}$. A volume of $1 \mathrm{~L}$ was extracted for a majority of samples. The cartridges were washed with $5 \mathrm{~mL}$ Millipore water and then dried using a vacuum pump topped with aluminum foil and then eluted with $10 \mathrm{~mL}$ of $0.25 \%$ ammonium hydroxide in methanol. The eluates were reduced to $150 \mu \mathrm{L}$ under a gentle stream of nitrogen $(>99.999 \%)$ and the mass-labeled $\left[{ }^{13} \mathrm{C}_{2}\right]$-PFOA and $\left[{ }^{13} \mathrm{C}_{8}\right]$-PFOA were added as injection standards $(10 \mu \mathrm{L}$, $100 \mathrm{pg} / \mu \mathrm{L})$. The samples from the Xiaoqing River were treated similarly, but only $400 \mathrm{~mL}$ of water were extracted. The dried cartridges were stored at $-20{ }^{\circ} \mathrm{C}$ until elution.

Instrumental Analysis. All samples were analyzed through a HPLC-MS/MS system using a HP 1100 LC system (Agilent Technologies) coupled to an API 3000 mass spectrometer (AB Sciex). Analysis was performed using negative electrospray ionization, with unit resolution in Q1 and Q3. MRM transitions for the target compounds are provided in Table S2. High performance liquid chromatography was performed using a Synergi $4 \mu \mathrm{m}$ Fusion-RP-C18 column $(150 \times 2 \mathrm{~mm}$; Phenomenex) combined with a SecurityGuard cartridge for Fusion-RP HPLC columns $(4 \times 2 \mathrm{~mm}$, Phenomenex $)$. The mobile phase consisted of A) water and B) methanol, both added with $10 \mathrm{mmol}$ ammonium acetate. The gradient profile was achieved at a flow rate of $200 \mu \mathrm{L} / \mathrm{min}$ and initiated with an equilibration of $70 \%$ A for $10 \mathrm{~min}$, which was decreased to $30 \%$ A for $3 \mathrm{~min}$ and to $10 \% \mathrm{~A}$ up to $29 \mathrm{~min}$, and then increased to $100 \% \mathrm{~B}$ up to $31 \mathrm{~min}$. $100 \% \mathrm{~B}$ was held for $14 \mathrm{~min}$. The column was heated constantly at $30{ }^{\circ} \mathrm{C}$.

Quality Assurance and Quality Control. Analytes were quantified using solvent based calibration curves obtaining the relative response of the target analyte to the amount of an appropriate mass-labeled internal standard. No appropriate internal standards were available for PFBS, PFPeA, and PFHpA. For those substances, internal standards with one or two carbon atoms longer or shorter were used. For HFPO-DA, $\left[{ }^{13} \mathrm{C}_{3}\right]$-HFPO-DA was only available for the extraction of the samples from the Rhine River. For the other samples, $\left[{ }^{13} \mathrm{C}_{2}\right]$ PFHxA was used, as recovery tests without matrix resulted in an accordance of $106 \pm 9 \%$. The mean recoveries of the internal standards ranged from $49 \pm 20 \%\left(\left[{ }^{13} \mathrm{C}_{4}\right]\right.$-PFOA $)$ to $98 \pm 70 \%$ $\left(\left[{ }^{13} \mathrm{C}_{5}\right]\right.$-PFNA). All calibration graphs were linear, and the correlation coefficients were $>0.99$ for all analytes. The calibration levels ranged from $0 \mathrm{pg} / \mu \mathrm{L}$ to $500 \mathrm{pg} / \mu \mathrm{L}$ (11point calibration). Higher concentration levels were added for HFPO-DA, PFBA, PFPeA, PFHpA, PFHxA, and PFOA when analyzing the samples from the Xiaoqing River. Some calculated concentrations had to be considered as semiquantitative, particularly for PFOA (Table S5). These concentrations were extremely high because of a strong point source near sampling site X10, which made a suitable calibration impracticable. Furthermore, diluting the samples was not a feasible option, as the concentration of the internal standards would be too low to be detected. If the calculated values were above the calibration range, then the real values would be even higher. However, the semiquantitative results should have no effect on the discussion of the Xiaoqing River results. The Limit of Detection (LOD) and the Limit of Quantification (LOQ) are defined as the concentration measured by the analytical instrument at a signalto-noise ratio $(S / N)$ of 3 and 10, respectively. Accordingly, the LOD and LOQ ranged from $0.1 \mathrm{pg}$ (PFOS) to $0.7 \mathrm{pg}$ (PFPeA) and from $0.3 \mathrm{pg}$ (PFOS) to $2.4 \mathrm{pg}$ (PFPeA), respectively. Methanol was regularly injected as an instrumental blank after injecting five samples. As all PTFE consisting parts had been removed or replaced by stainless steel, polyethylene, or polypropylene, the methanol blanks did not register instrumental contamination. At least five procedural blank samples were extracted with the water samples. The blank contaminations distinguished among the sample batches which were extracted at varying times and locations. The method blank concentrations were taken into consideration when calculating sample concentrations. For the analytes present in the method blanks, the Method Detection Limit (MDL) and the Method Quantification Limit (MQL) were calculated with the blank standard deviations multiplied by the variable from the Student's $t$ table at $98 \%$ confidence $^{28}$ and by a factor of 10 , respectively. For the analytes absent in the method blanks, the sample with the lowest concentration was chosen to extrapolate from the calculated $S / N$ at this concentration to a $S / N$ of 3 and 10 , respectively. All values, including the LODs, LOQs, MDLs, MQLs, and mean recoveries, are listed in the Tables S3 and S4.

Principal Component Analysis. The Kaiser-Meyer-Olkin measure of sampling adequacy (KMO) was calculated using SPSS Statistics 22 software (IBM, Armonk, NY) to determine the appropriateness of the data set for Principal Component Analysis (PCA). The KMO was calculated to be 0.804 , suggesting the data set as suitable for PCA. ${ }^{29}$ PCA was applied using OriginPro 9.1G software (OriginLab Corporation, Northampton, MA) to compare statistically the PFASs distribution patterns among sampling sites and to identify the factors that mostly influence the sampling sites. Five principal components were retained as they cumulatively contributed to more than $90 \%$ of total variation in the data set. ${ }^{30}$ Raw data (measured PFASs concentrations) was normalized by subtracting the average concentration of each compound from the individual concentrations and dividing through the standard deviation. Principal Component 1 (PC1), Principal Component 2 (PC2), and Principal Component 3 (PC3) contributed $49.34 \%, 21.46 \%$, and $12.44 \%$ to total variation in the data set, respectively. The score and loading plots for PC1 and PC2 and for PC2 and PC3 are given in the Supporting Information (Figures S6 and S7).

\section{RESULTS AND DISCUSSION}

Spatial Distribution of PFASs. The spatial distribution of PFASs was investigated in the Lower Rhine and its branch streams (R1 to R23); the Elbe River (E1 to E22); the nearshore zone of the North Sea, including the Elbe estuary, the Lower Weser, and the Lower Ems (T1-T19 and S1-S18); and the 


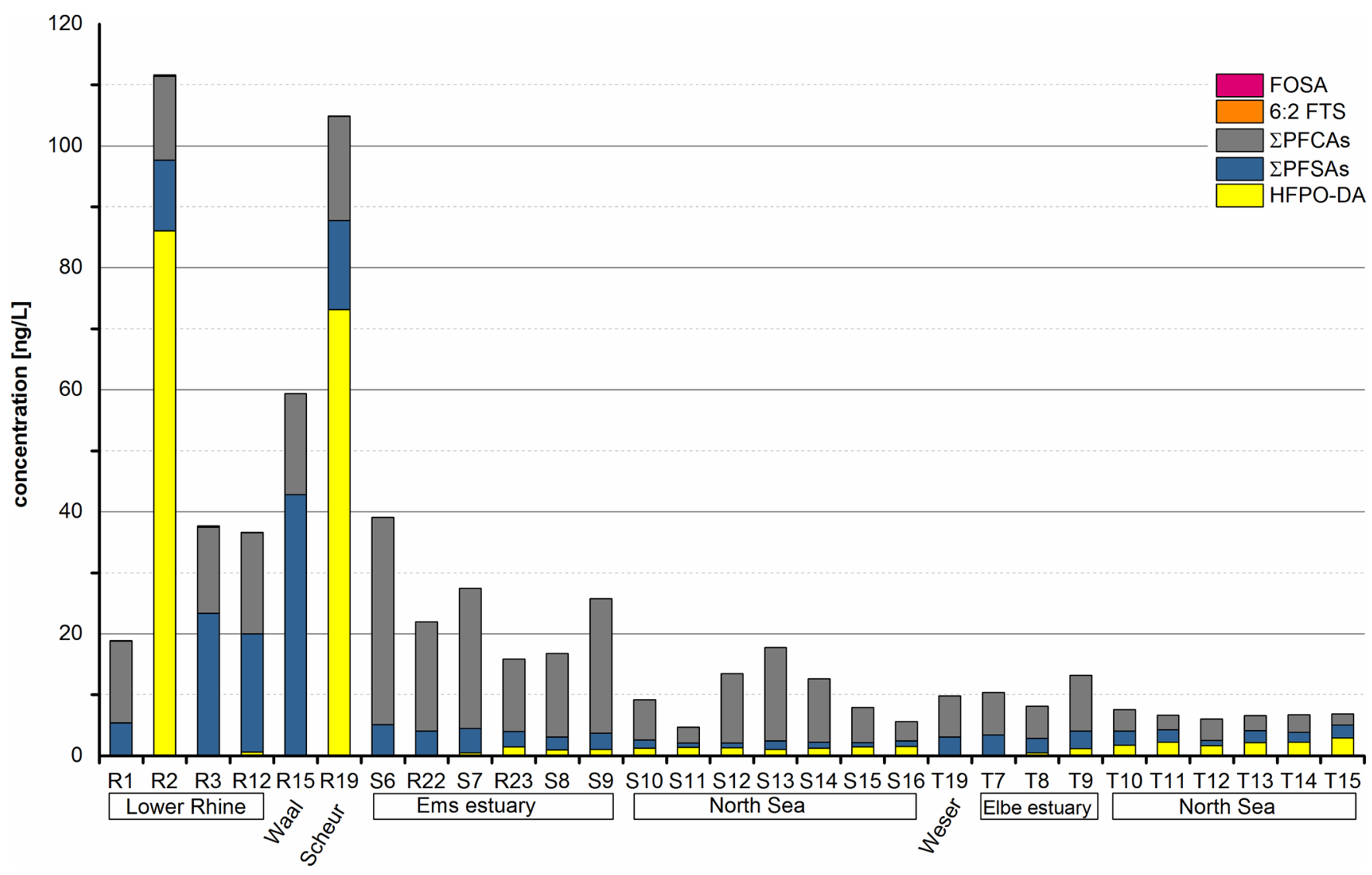

Figure 2. PFASs concentrations $[\mathrm{ng} / \mathrm{L}]$ in selected surface water samples from the Lower Rhine and its branch streams Waal and Scheur (R1-R19, August 2013), from the Ems estuary (S6-S9, August 2014 and R22-R23, August 2013), from the North Sea (S10-S16, August 2014 and T10T15, March 2014), from the Weser (T19, March 2014), and from the Elbe estuary (T7-T9, March 2014).

Xiaoqing River, including the Laizhou Bay (X1-X29) (Figure 1). The alternative substance HFPO-DA and 14 legacy perfluoroalkyl substances were detected. PFASs concentrations at all sampling sites are illustrated in Table S5, and the detection frequencies, as well as the maximum, minimum, mean, and median for the analyte concentrations, are highlighted in Table S6. To the best of our knowledge, this study is the first to report quantitative measurements of the fluorinated replacement substance HFPO-DA in surface water.

PFASs in the Lower Rhine and its Branch Streams. HFPO-DA, as well as 13 legacy PFASs, were quantified along the Lower Rhine and its branch streams, including the Ems estuary (Figure 2). The $\Sigma$ PFASs concentrations ranged from $15.9 \mathrm{ng} / \mathrm{L}$ at the city of Cologne (R1) to $111 \mathrm{ng} / \mathrm{L}$ at the city of Leverkusen (R2). The pollution burden at station R1 was relatively low; it greatly increased at station $\mathrm{R} 2$ where a lot of industrial sites are located. Since 2007, the North-RhineWestphalia State Environment Agency (LANUV) has offered to support companies in reducing their discharges of PFASs into the environment. ${ }^{31}$ Consequently, total concentrations of PFASs were found to be below the LANUV predefined guideline limit of $1 \mu \mathrm{g} / \mathrm{L}$. However, the alternative substance HFPO-DA was the dominant compound detected, with a remarkably high concentration of $86.1 \mathrm{ng} / \mathrm{L}$ at sampling site $\mathrm{R} 2$ in Leverkusen. It is noteworthy that the concentration of HFPO-DA was approximately three times higher than that of the sum of legacy PFASs. Moreover, HFPO-DA was detected in a relatively low concentration of $0.6 \mathrm{ng} / \mathrm{L}$ downstream at station R12, close to the German-Dutch border. Between sampling sites R2 and R12, HFPO-DA was not detected. As HFPO-DA has an estimated low $\mathrm{p} K_{\mathrm{a}}$ value of 0.06 , a high water solubility of $7.1 \mathrm{~g} / \mathrm{L}$, and a half-life in water of $17280 \mathrm{~h},{ }^{32}$ the detection of HFPO-DA may have resulted from a temporary, discontinuous or accidental discharge of this chemical upstream of sampling site R2. Therefore, it is possible that we measured the maximum concentration of a pollution wave that dropped sharply due to dilution and dispersion processes. ${ }^{33}$ As this result stems from a single measurement, it could be that HFPO-DA was observed accidentally.

A second point source of HFPO-DA appears to be located near sampling site R19 in the city of Rozenburg-Rotterdam in the branch stream Scheur, which is a part of the Rhine-Meuse delta. There it was detected at a concentration of $73.1 \mathrm{ng} / \mathrm{L}$, a magnitude comparable to that of sampling site R2 and, similarly, approximately two times greater than that of the sum of legacy PFASs. In 2008, the dominant compound at this sampling site was PFBA at a concentration of $105 \mathrm{ng} / \mathrm{L} \cdot{ }^{34} \mathrm{~A}$ possible source of contamination is the Port of Rotterdam with more than 45 chemical plants situated here. ${ }^{35}$ The city of Dordrecht may also be a source area, because some fluoropolymer manufacturing industry is located there. ${ }^{36}$ HFPO-DA was not detected in the Old Meuse; however, it could have been transported through the Noord and New Meuse Rivers to the Scheur and ultimately into the North Sea, as it was detected at a concentration of $1.4 \mathrm{ng} / \mathrm{L}$ at station R23 in the Ems estuary.

The main legacy PFASs were PFBS, PFPeA, and PFOA with average concentrations of $15.6 \pm 9.2 \mathrm{ng} / \mathrm{L}, 4.7 \pm 1.7 \mathrm{ng} / \mathrm{L}$, and 

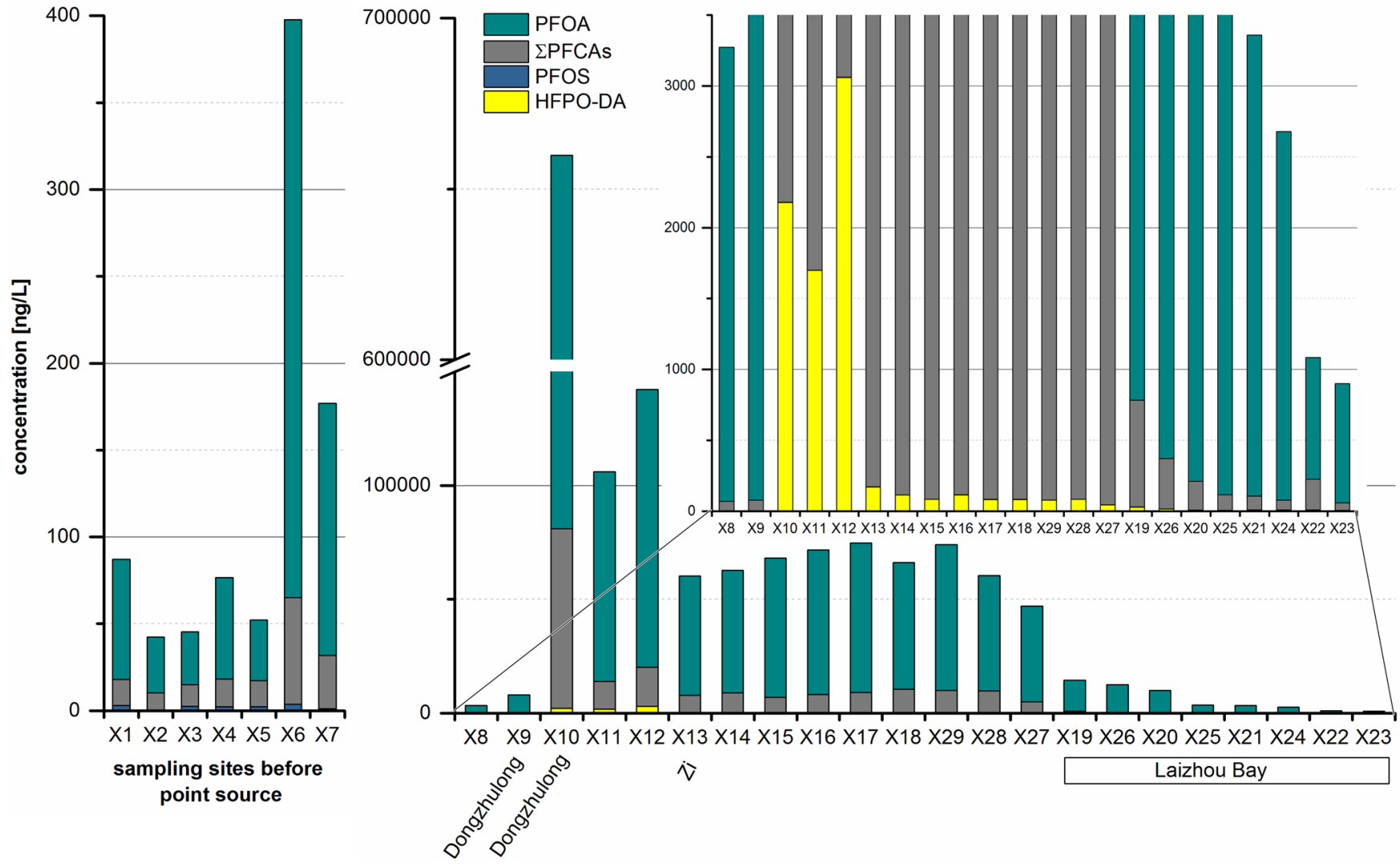

Figure 3. PFASs concentrations $[\mathrm{ng} / \mathrm{L}]$ in surface water along the Xiaoqing River including the tributaries Dongzhulong and Zi and Laizhou Bay.

$4.8 \pm 1.0 \mathrm{ng} / \mathrm{L}$, respectively. PFBS had higher variations compared with PFPeA and PFOA. The highest PFBS concentration of $40 \mathrm{ng} / \mathrm{L}$ was detected in the Waal River at station R15. Comparing our results with those from 2008, ${ }^{34}$ PFBS pollution was approximately five times lower, most likely due to reducing its discharge into wastewater. ${ }^{31}$ Additionally, PFHxS, PFBA, PFHxA, PFHpA, PFNA, and PFDA were detected in all samples. PFOS was detected in $74 \%$ of the samples, FOSA in $87 \%$ of the samples, $6: 2$ FTS in $26 \%$ of the samples, and PFDoDA in one sample.

PFASs in the Elbe River. Fourteen legacy PFASs were quantified along the Elbe River (Figure S5). PFBS, PFHxS, PFPeA, PFHXA, PFOA, and PFNA were detected in all samples. PFBA and PFUnDA were detected in $91 \%$ of the samples. PFDA was detected in $95 \%$, PFHpA in $68 \%$, FOSA in 64\%, 6:2 FTS in 59\%, PFDoDA in 50\%, and PFOS in 36\% of the samples. The $\Sigma$ PFASs concentration ranged from $4.6 \mathrm{ng} / \mathrm{L}$ at the city of Dömitz (E15) to $27.2 \mathrm{ng} / \mathrm{L}$ at the city of Glückstadt (E21). As expected, levels were lower than those from the Lower Rhine. In general, PFASs pollution in the Elbe River results from diffuse sources rather than from industrial point sources. This hypothesis is statistically supported by the results from PCA. As Figure S6 illustrates, the sampling sites from the Elbe River are mainly situated on the positive side of PC2, whereas the sampling sites from the Rhine River are dominant on the negative side of PC1. Comparing PC2 with PC3, the separation of the study areas becomes even more obvious (Figure S7). The compounds PFBS and PFHxS are major contributors to PC3, whereas PFDoDA, PFUnDA, 6:2 FTS, and FOSA are major contributors to PC2, indicating that these compounds, which may come from different sources, are mainly responsible for separating the Elbe River samples from the Rhine River samples.

The dominant compounds in all samples were PFBS, PFPeA, and PFHxA, with average concentrations of $2.3 \pm 0.7 \mathrm{ng} / \mathrm{L}, 2.4$ $\pm 1.4 \mathrm{ng} / \mathrm{L}$, and $2.8 \pm 0.6 \mathrm{ng} / \mathrm{L}$, respectively. High $\Sigma$ PFASs concentrations were detected in samples close to the city of Hamburg and downstream of the city, particularly resulted from an increase of PFOS after the barrage in Geesthacht which is located between sampling sites E17 and E18. In 2006, an increase of the PFOS concentration by approximately $190 \%$ was detected close to the same location. ${ }^{27}$ However, the $\Sigma$ PFASs concentration of $21.5 \mathrm{ng} / \mathrm{L}$ is lower than in 2006 $(50.7 \mathrm{ng} / \mathrm{L})^{27}$ and similar to $2011(15 \mathrm{ng} / \mathrm{L}) .^{37}$ Another local source of PFOS pollution appears to be located near sampling site E6, where the highest concentration, $10.5 \mathrm{ng} / \mathrm{L}$, was detected. In 2008, a PFOS concentration of $6.7 \mu \mathrm{g} / \mathrm{L}$ was detected in the same area of the Elbe River. ${ }^{38}$ Although the current concentration is much lower than six years ago, the unknown source potentially still exists. PFHpA was not detected between sampling sites E1 and E7, whereas $1.7 \mathrm{ng} /$ $\mathrm{L}$ was observed at station E8. This increase in levels could be the result of a nearby chemical plant that produces cleaning agents and other products. The concentration decreased at subsequent stations and increased again after the barrage in Geesthacht (E18). The substance 6:2 FTS was detected in samples mainly from the Upper Elbe and partially from the Middle Elbe. The source may be film-forming fluorinated surfactants used, for example, in aqueous film-forming foams (AFFF). The surfactants are based on perfluoroalkyl betaine, which ultimately could degrade to 6:2 FTS and PFHxA. ${ }^{31,39}$

Transport of PFASs into the North Sea. As mentioned previously, the fluorinated alternative HFPO-DA was detected 
in the Ems estuary in August 2013 (R23). To locate the source of HFPO-DA pollution and to investigate whether it is equally present in the German Bight, two sampling campaigns were conducted along the German and Dutch coast in March and August 2014. HFPO-DA, as well as 11 legacy PFASs, were quantified in the coastal region of the North Sea, including the estuaries of the Elbe, Weser, and Ems Rivers (Figure 2). The $\Sigma$ PFASs concentrations ranged from $3.9 \mathrm{ng} / \mathrm{L}$ in the German Bight (S2) to $39.1 \mathrm{ng} / \mathrm{L}$ in the Ems River (S6). In general, the $\Sigma$ PFASs concentrations decreased as seawater dilution increased.

HFPO-DA was detected in all samples along the coastline with average concentrations of $1.8 \pm 0.8 \mathrm{ng} / \mathrm{L}$ in March and 1.2 $\pm 0.3 \mathrm{ng} / \mathrm{L}$ in August 2014. The substance was not detected in the Elbe, Weser, and Ems Rivers but was detected in a few samples taken from their estuaries (T8-T9 and S7-S9). These samples had been affected by seawater, as salinity levels were above 9.5 practical salinity units (psu). HFPO-DA was the dominant compound in the samples taken from the German Bight in March 2014 (T10-T15). In the samples from August 2014, the substance was dominant along with PFOA and PFHpA, except in the samples from the Ems estuary. The results confirm that the fluorinated alternative HFPO-DA has not been transported through the Elbe, Weser, and Ems Rivers into the German Bight. We hypothesize that its contamination originates from the Rhine-Meuse-delta and has been transported via the water current ${ }^{40}$ along the coastline of the German Bight. A similar assumption has been made to explain higher PFBS concentrations in the German Bight than in the Elbe River in $2009 .^{27}$

The legacy PFASs (PFHxS, PFPeA, PFNA, PFDA, and PFUnDA) were found mainly in the estuaries. Nevertheless, slightly elevated $\Sigma$ PFASs concentrations were found at sampling sites T9, S9, and between S12 and S14. Results at T9 primarily showed an increase in PFOA, which could be attributed to its proximity to the harbor of Cuxhaven. The sample from site S9 showed mainly an increase in PFHpA and PFOA and was possibly affected by the Ems canal connecting the cities of Groningen and Delfzijl. Generally, a higher average $\Sigma$ PFASs concentration was observed in the Ems (36.6 \pm $3.5 \mathrm{ng} / \mathrm{L})$ than in the Elbe and Weser Rivers $(10.6 \pm 1.2 \mathrm{ng} / \mathrm{L}$ and $12.1 \pm 2 \mathrm{ng} / \mathrm{L}$, respectively). The $\Sigma$ PFASs concentration in the Elbe estuary was lower in March 2014 than in September 2014, which suggests a possible seasonal influence, also noticed in 2011 . $^{37}$

PFASs in the Xiaoqing River. HFPO-DA and 10 legacy PFASs were quantified along the Xiaoqing River (Figure 3). The $\Sigma$ PFASs concentrations ranged from $42.4 \mathrm{ng} / \mathrm{L}$ near the city of Jinan (X2) to $660 \mu \mathrm{g} / \mathrm{L}$ in the Dongzhulong River (X10), implying an increase in $\Sigma$ PFASs concentration by 4 orders of magnitude. The fluorinated alternative HFPO-DA was detected in $76 \%$ of the samples with a maximum level of $3.1 \mu \mathrm{g} / \mathrm{L}$ at site $\mathrm{X} 12$, which is approximately 36 times higher than the concentration caused by the point source in the Rhine River. Nevertheless, HFPO-DA - and likewise the shorterchained PFCAs - was a minor component in the Chinese samples compared with the dominant compound PFOA, which made up the highest proportion, $87 \pm 9 \%$, in all samples. Interestingly, no short-chain sulfonic acids were detected, and PFOS was only observed in low concentrations or below the MDL. A likely explanation for these results is that the sulfonic acids were neither manufactured nor widely applied in industrial processes in this region. ${ }^{41}$ Based on the results from PCA, PC1 was characterized by high loadings of HFPODA and PFCAs with a chain length of $C_{4}$ to $C_{10}$ (Figure S6). Thus, these compounds mainly contribute to a separation of the Xiaoqing River samples from the European samples, indicating a different source of pollution among the areas of study. Concentration levels of the long-chain carboxylic acids PFDA, PFUnDA, and PFDoDA were similar to those from the Elbe River or below the MDL, indicating that they are less relevant in surface waters of the Xiaoqing River.

The $\Sigma$ PFASs concentrations between sampling sites X1 and $\mathrm{X} 5$ were of a similar level compared to samples from the Rhine River, followed by an 8 -fold increase at X6, primarily caused by PFOA and PFBA. The $\Sigma$ PFASs concentration decreased from $\mathrm{X} 6$ to $\mathrm{X} 7$ and then increased rapidly to $\mathrm{X} 8$ by a factor of 19 . The sampling sites $\mathrm{X} 7$ and $\mathrm{X} 8$ are in close proximity; however, the Shengli River flows into the Xiaoqing River between these two sites, indicating that this tributary directly impacts the PFASs pollution of the Xiaoqing River. It is possible that smaller fluoropolymer manufacturing sites which are located in the region of Zouping county are responsible for the increased concentrations from sampling site X6. ${ }^{24}$ Along the Xiaoqing River, a high $\Sigma$ PFASs concentration of $106 \mu \mathrm{g} / \mathrm{L}$ was observed at station X11, which has been attributed to a substantial point source in proximity to sampling site X10 located in the tributary Dongzhulong. PFOA was the dominant compound detected, with a concentration of $579 \mu \mathrm{g} / \mathrm{L}$, whereas the PFHpA, PFHxA, PFPeA, PFBA, HFPO-DA, PFNA, PFDA, and PFUnDA concentration was $80.9 \mu \mathrm{g} / \mathrm{L}$. The percentage of these compounds was only $13 \%$; however, their concentrations were considerably higher compared with the concentrations in the Rhine and Elbe Rivers. The levels from sampling site X10 totaled approximately 6000 times that of sampling site R2 in the Rhine River. The difference between the concentration levels may be due to both higher production volumes and less current technological standards at the wastewater treatment facility. Such high concentrations are almost certainly caused primarily by industrial discharges from fluorochemical or fluoropolymer manufacturing sites. This hypothesis is supported by the fact that, to the best of our knowledge, this area is home to Asia's largest industrial park for fluorine- and siliconbased products, including manufacturing sites for polytetrafluoroethylene (PTFE), tetrafluoroethylene (TFE), and other fluorinated and fluoropolymer fine chemicals with production capacities of several hundred thousand tons per year. ${ }^{24}$ In 2011, high concentrations of PFOA were found in human blood samples from Zouping, a neighboring district to Huantai, where the industrial park is located. ${ }^{42}$ Our results reveal that the fluoropolymer industry located in the North of Zibo seriously impact the Dongzhulong River, and consequently the Xiaoqing River and the Laizhou Bay, as the following sampling sites are strongly affected by the point source, as described below.

The $\Sigma$ PFASs concentrations decreased by a factor of 6 from the sampling sites $\mathrm{X} 10$ to $\mathrm{X} 11$, followed by a recurring increase at X12. However, PFBA showed a marginally lower concentration at station X12 than at X11. Although the $\Sigma$ PFASs concentration at station $\mathrm{X} 12$ was lower than at station X10, HFPO-DA was the only compound that registered a slightly higher concentration, $3.1 \mu \mathrm{g} / \mathrm{L}$, than at station $\mathrm{X} 10$ $(2.2 \mu \mathrm{g} / \mathrm{L})$. It is possible that the Shengli River contributes to the PFASs pollution of the Xiaoqing River (Figure 1). Other tributaries, such as the $\mathrm{Zi}$ and Zhinve Rivers, may also impact the PFASs pollution levels of the Xiaoqing River, because the $\Sigma$ PFASs concentrations increased slightly until sampling site 
X17. However, it is uncertain what the sources of PFASs are, and it could be that these tributaries are likewise directly influenced by the fluoropolymer industry at the Dongzhulong River due to a strongly interconnected waterway network. In 2011, a $\Sigma$ PFASs concentration of $5.1 \mu \mathrm{g} / \mathrm{L}$ was detected near sampling site X12. ${ }^{24}$ Comparing our results with those from 2011, we found an increase in the total concentration by a factor of approximately 28 .

From sampling site X17, the concentrations of HFPO-DA decreased to levels similar to the European sampling sites R2 and R19. In general, $\mathrm{PPFASs}$ concentrations declined steadily toward Laizhou Bay due to dilution with fresh seawater. The concentrations are, however, significantly higher than before the point source input. Because Laizhou Bay is a fishing area and home to numerous macrobenthic species, ${ }^{25}$ the impact of the PFASs pollution from the Xiaoqing River can be considered harmful to the aquatic life. However, there are no official limits on the amount of PFASs in surface water. In Germany, for example, it is the task of individual states to establish limits for levels of PFASs in surface water. As mentioned previously, the North-Rhine-Westphalia State Environment Agency set a guideline limit of $1 \mu \mathrm{g} / \mathrm{L}$ for the sum of 10 PFASs in discharged wastewater. ${ }^{31}$ This guideline limit was exceeded in $72 \%$ of the Chinese samples. Some German states, such as Bavaria, evaluate their surface waters based on the PNEC (Predicted-No-Effect-Concentration), which represents the concentration of a chemical which has no predicted effect on species in the environment. ${ }^{43}$ The PNEC $_{\text {aquatic }}$ is only available for PFOA $(570 \mu \mathrm{g} / \mathrm{L})^{44}$ and PFOS $(0.05 \mu \mathrm{g} / \mathrm{L}),{ }^{43}$ because necessary toxicity data for the individual PFASs in different aquatic species is limited. The $\mathrm{PNEC}_{\text {aquatic }}$ for PFOA was marginally exceeded in sample X10 from the Dongzhulong River.

Comparison of PFASs Distribution Patterns between European and Chinese River/Estuary Systems. Figure 4

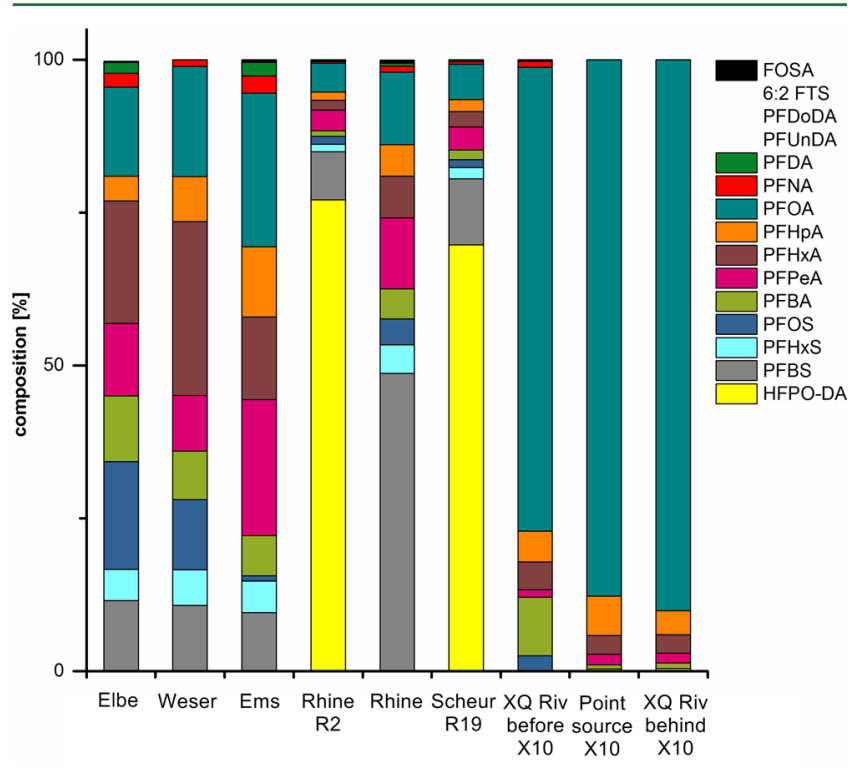

Figure 4. Average contribution of individual PFASs to $\Sigma$ PFASs in the Lower Elbe (T1-T7 and E19-E21), Weser (T16-T19), Ems (S5S6 and R21-R22), Rhine (R2), Rhine (R3-R13), Scheur (R19), Xiaoqing River before the point source $(\mathrm{X} 1-\mathrm{X} 7)$, Dongzhulong near the point source (X10), and in the Xiaoqing River behind the point source (X11-X12 and X14-X29). illustrates the distribution patterns of PFASs, which was examined on a proportional basis, highlighting the significant differences between the river/estuary systems. Comparing the Elbe, Weser, and Ems Rivers as discharging rivers into the North Sea, the distribution pattern is characterized by a variety of legacy perfluoroalkyl compounds, assuming that the pollution is caused by diffuse sources rather than by point sources. In contrast, we observed two point sources along the Rhine River as well as in the Rhine-Meuse delta, where the fluorinated alternative HFPO-DA was the dominant compound with percentages of $77 \%$ and $70 \%$, respectively, and concentrations 16 or 12 times higher than concentrations of its predecessor substance PFOA. In Germany and The Netherlands, we did not observe a current industrial discharge source of PFOA; however, driven by concerns around the use of long-chain and possibly short-chain PFASs, industry seems to respond by using replacement substances like HFPO-DA. Along the Dongzhulong River, we observed a high rate of industrial discharge of PFASs in general and PFOA in particular probably due to both the strong demand for PFASs-based products and the outsourcing of a large part of the fluoropolymer industry to China in response to actual and pending regulations in Europe. The worldwide demand for high-quality PTFE products still results in high emissions of PFOA at fluoropolymer manufacturing sites. However, its replacement substance HFPO-DA was detected in concentrations up to 42 times greater in China than in Germany and The Netherlands. Along the Dongzhulong and Xiaoqing Rivers, we observed an increase in concentrations of 490 and 644 times, respectively. Hence, as HFPO-DA is environmentally persistent and chemically stable, its detection in the aquatic environments of both Europe and China is of concern. Moreover, HFPO-DA has similar physicochemical properties (high water solubility and low $\mathrm{p} K_{\mathrm{a}}$ ) and similar long-range transport potential indicators (characteristic travel distance CTD and overall persistence $P_{\text {ov }}$ ) to those of PFOA or its dissociated anionic form, indicating that they may have the same ability to be transported from the river/estuary systems and coastal regions to remote areas via ocean currents. ${ }^{32}$ In addition, specific target organ toxicity can occur under prolonged or repeated exposure, suggesting a similar mode of toxic action as of PFOA. ${ }^{17}$ The structural similarity to PFOA also implies that HFPO-DA cannot be metabolized in biota and may have a similar high affinity to proteins, resulting in a potential for bioaccumulation. ${ }^{45}$ However, future studies are necessary to fully understand the fate and behavior of HFPODA in the environment.

\section{ASSOCIATED CONTENT}

\section{S Supporting Information}

Tables S1-S6 and Figures S1-S7. The Supporting Information is available free of charge on the ACS Publications website at DOI: $10.1021 /$ acs.est.5b01648.

\section{AUTHOR INFORMATION}

\section{Corresponding Authors}

*Phone: 49-4152-87-2353. Fax: 49-4152-87-2332. E-mail: franziska.heydebreck@hzg.de.

*Phone: 86-535-2109151. Fax: 86-535-2109000. E-mail: jhtang@yic.ac.cn.

Notes

The authors declare no competing financial interest. 


\section{ACKNOWLEDGMENTS}

This work was supported by the Key Research Programs of the Chinese Academy of Sciences (KZZD-EW-14, 133337KYSB20130013, and XDA11020402). The authors thank Runmei Wang, Danijela Kötke, and the crew of the $R$ / $V$ Ludwig Prandtl for their assistance during the sampling campaign, Wenying $\mathrm{Mi}$ for her assistance in the laboratory, Hendrik Wolschke for organizing one sampling campaign, Jürgen Gandraß for his advice on mass spectrometry, Daniel Neumann for his help on principal component analysis, and Renate Sturm for her suggestions regarding the manuscript.

\section{REFERENCES}

(1) Buck, R. C.; Franklin, J.; Berger, U.; Conder, J. M.; Cousins, I. T.; de Voogt, P.; Jensen, A. A.; Kannan, K.; Mabury, S. A.; van Leeuwen, S. P. Perfluoroalkyl and polyfluoroalkyl substances in the environment: terminology, classification, and origins. Integr. Environ. Assess. Manage. 2011, 7 (4), 513-541.

(2) Scheringer, M.; Trier, X.; Cousins, I. T.; de Voogt, P.; Fletcher, T.; Wang, Z.; Webster, T. F. Helsingor statement on poly- and perfluorinated alkyl substances (PFASs). Chemosphere 2014, 114, 337-339.

(3) UNEP. Stockholm Convention on Persistent Organic Pollutants. http://www.pops.int/documents/convtext/convtext_en.pdf (accessed June 2, 2015)

(4) ECHA European Chemicals Agency. Candidate List of substances of very high concern for Authorisation. http://echa. europa.eu/candidate-list-table (accessed January 16, 2015).

(5) ANNEX XV PROPOSAL FOR A RESTRICTION - Perfluorooctanoic acid (PFOA), PFOA salts and PFOA-related substances, Version 1.0; ECHA European Chemicals Agency: Helsinki, Finland, 2014. http://echa.europa.eu/documents/10162/e9cddee6-3164-473db590-8fcf9caa50e7 (accessed June 2, 2015).

(6) Ritter, S. K. Fluorochemicals go short. Chem. Eng. News 2010, 88 (5), 12-17.

(7) FluoroCouncil. Global Regulatory Activity on Long Chain Perfluorochemicals and Fluoropolymers. Spring Fluoropolymers Division Conference, Miami Beach, FL, Jan 24-26, 2012.

(8) Quinete, N.; Orata, F.; Maes, A.; Gehron, M.; Bauer, K. H.; Moreira, I.; Wilken, R. D. Degradation studies of new substitutes for perfluorinated surfactants. Arch. Environ. Contam. Toxicol. 2010, 59 (1), 20-30.

(9) Rayne, S.; Forest, K. Perfluoroalkyl sulfonic and carboxylic acids: a critical review of physicochemical properties, levels and patterns in waters and wastewaters, and treatment methods. J. Environ. Sci. Health, Part A: Toxic/Hazard. Subst. Environ. Eng. 2009, 44 (12), 1145-1199.

(10) Vierke, L.; Moller, A.; Klitzke, S. Transport of perfluoroalkyl acids in a water-saturated sediment column investigated under nearnatural conditions. Environ. Pollut. 2014, 186, 7-13.

(11) Hoke, R.; Ferrell, B.; Sloman, T.; Bloxham, P.; Buxton, W. WP 214 Acute and Chronic Aquatic Toxicity and Bioconcentration Assessment of a Perfluorinated Aliphatic Carboxylic Acid, (C6HF11O3.H3N). 33rd SETAC North America Annual Meeting, Long Beach, USA, Nov 11-15, 2012.

(12) Gordon, S. C. Toxicological evaluation of ammonium 4,8-dioxa$3 \mathrm{H}$-perfluorononanoate, a new emulsifier to replace ammonium perfluorooctanoate in fluoropolymer manufacturing. Regul. Toxicol. Pharmacol. 2011, 59 (1), 64-80.

(13) Strynar, M.; Dagnino, S.; Lindstrom, A.; Andersen, E.; McMillan, L.; Thurman, M.; Ferrer, I.; Ball, C. Identification of novel polyfluorinated compounds in natural waters using accurate mass TOFMS. 33rd SETAC North America Annual Meeting, Long Beach, USA, Nov $11-15,2012$.

(14) Wang, Z.; Cousins, I. T.; Scheringer, M.; Hungerbühler, K. Fluorinated alternatives to long-chain perfluoroalkyl carboxylic acids (PFCAs), perfluoroalkane sulfonic acids (PFSAs) and their potential precursors. Environ. Int. 2013, 60, 242-248.
(15) Millauer, H.; Schwertfeger, W.; Siegemund, G. Hexafluoropropene Oxide - A Key Compound in Organofluorine Chemistry. Angew. Chem., Int. Ed. Engl. 1985, 24 (3), 161-179.

(16) DuPontTM GenX processing aid for making fluoropolymer resins; DuPont: 2010. http://www2.dupont.com/Industrial_Bakery_ Solutions/en_GB/assets/downloads/DuPont_GenX_Brochure Final_07July2010.pdf (accessed June 2, 2015).

(17) ECHA European Chemicals Agency. Registered substances Ammonium 2,3,3,3-tetrafluoro-2-(heptafluoropropoxy)propanoate. http://echa.europa.eu/information-on-chemicals/registeredsubstances (accessed March 16, 2015).

(18) PFOA- und ADONA-Messungen an der Probenahmestelle Alz/ Hohenwarth; Bayerisches Landesamt für Umwelt: Augsburg, 2010. http://www.lfu.bayern.de/analytik stoffe/analytik org stoffe perfluorierte_chemikalien/doc/pfoa_adona_alz.pdf (accessed June 2, 2015).

(19) Wang, S.; Huang, J.; Yang, Y.; Hui, Y.; Ge, Y.; Larssen, T.; Yu, G.; Deng, S.; Wang, B.; Harman, C. First Report of a Chinese PFOS Alternative Overlooked for 30 Years: Its Toxicity, Persistence, and Presence in the Environment. Environ. Sci. Technol. 2013, 47, 1016310170 .

(20) Verkehrsbericht 2010; Wasser- und Schifffahrtsdirektion Südwest: Mainz, 2010. http://www.ast-suedwest.gdws.wsv.de/wir ueber_uns/service/Publikation/pdf/Verkehrsbericht-2010.pdf (accessed June 2, 2015)

(21) Netzband, A.; Reincke, H.; Bergemann, M. The River Elbe - A Case Study for the Ecological and Economical Chain of Sediments. J. Soils Sediments 2002, 2 (3), 112-116.

(22) Nord, S. Bevölkerungsstand, Bevölkerungsdichte und Bevölkerung nach Altersgruppen am 31.12.2011. 2014.

(23) Tümmers, H. J. Der Rhein: ein europäischer Fluss und seine Geschichte, 2nd ed.; C. H. Beck: München, 1999.

(24) Wang, P.; Lu, Y.; Wang, T.; Fu, Y.; Zhu, Z.; Liu, S.; Xie, S.; Xiao, Y.; Giesy, J. P. Occurrence and transport of 17 perfluoroalkyl acids in 12 coastal rivers in south Bohai coastal region of China with concentrated fluoropolymer facilities. Environ. Pollut. 2014, 190, 115122.

(25) Luo, X.; Zhang, S.; Yang, J.; Pan, J.; Tian, L.; Zhang, L. Macrobenthic community in the Xiaoqing River Estuary in Laizhou Bay, China. J. Ocean Univ. China 2013, 12 (3), 366-372.

(26) Zhao, Z.; Tang, J.; Xie, Z.; Chen, Y.; Pan, X.; Zhong, G.; Sturm, R.; Zhang, G.; Ebinghaus, R. Perfluoroalkyl acids (PFAAs) in riverine and coastal sediments of Laizhou Bay, North China. Sci. Total Environ. 2013, 447, 415-423.

(27) Ahrens, L.; Plassmann, M.; Xie, Z.; Ebinghaus, R. Determination of polyfluoroalkyl compounds in water and suspended particulate matter in the river Elbe and North Sea, Germany. Front. Environ. Sci. Eng. China 2009, 3 (2), 152-170.

(28) Goulden, C. H. Methods of Statistical Analysis, 2nd ed.; Wiley: New York, 1956.

(29) Kaiser, H. F. An Index of Factorial Simplicity. Psychometrika 1974, 39 (1), 31-36.

(30) Jolliffe, I. T. Principal Component Analysis, 2nd ed.; Springer: New York, 2002.

(31) Verbreitung von PFT in der Umwelt: Ursachen - Untersuchungsstrategie - Ergebnisse - Maßnahmen (LANUV Fachbericht 34). www. lanuv.nrw.de (accessed June 2, 2015).

(32) Gomis, M. I.; Wang, Z.; Scheringer, M.; Cousins, I. T. A modeling assessment of the physicochemical properties and environmental fate of emerging and novel per- and polyfluoroalkyl substances. Sci. Total Environ. 2015, 505, 981-991.

(33) Kühlers, D.; Bethge, E.; Fleig, M.; Hillebrandt, G.; Hollert, H.; Lehmann, B.; Maier, D.; Maier, M.; Mohrlok, U.; Wölz, J. Spannungsfeld Hochwasserrückhaltung und Trinkwassergewinnung; KIT Scientific Publishing: Karlsruhe, 2010.

(34) Möller, A. Analysis of poly- and perfluoroalkyl compounds (PFCs) in surface water of the River Rhine using HPLC-MS/MS. Hamburg, 2009. 
(35) Facts \& Figures - Rotterdam Energy Port and Petrochemical Cluster; Port of Rotterdam Authority: 2010. http://www. portofrotterdam.com/de/Brochures/Facts-Figures-Rotterdam-EnergyPort-and-Petrochemical-Cluster.pdf (accessed June 2, 2015).

(36) Certificate of Approval - ISO 14001:2004; http://corian.hu/ Sustainability/en_US/sustain_action/e.i._dupont_iso_14001_ certificate.pdf (accessed June 2, 2015).

(37) Zhao, Z.; Xie, Z.; Tang, J.; Sturm, R.; Chen, Y.; Zhang, G.; Ebinghaus, R. Seasonal variations and spatial distributions of perfluoroalkyl substances in the rivers Elbe and lower Weser and the North Sea. Chemosphere 2014, 129, 118-125.

(38) Ullrich, K. Perfluorierte Tenside (PFT) in Gewässern und Abwasserbehandlungsanlagen des Bundeslandes Sachsen. Diplomarbeit, Fachhochschule Magdeburg-Stendal, 2008.

(39) Hähnle, J.; Arenholz, U. Ersatz von perfluorierten Tensiden (PFT) durch neue polyfluorierte Tenside in Feuerlöschschaummitteln - Nachweisproblematik und Umweltrelevanz. vfdb-Zeitschrift für Forschung, Technik und Management im Brandschutz 2011, 1, 18-23.

(40) Laevastu, T. Water types in the North Sea and their characteristics; Hawaii Institute of Geophysics Report No. 24; University of Hawaii: 1962.

(41) Xie, S.; Wang, T.; Liu, S.; Jones, K. C.; Sweetman, A. J.; Lu, Y. Industrial source identification and emission estimation of perfluorooctane sulfonate in China. Environ. Int. 2013, 52, 1-8.

(42) Guo, F.; Zhong, Y.; Wang, Y.; Li, J.; Zhang, J.; Liu, J.; Zhao, Y.; $\mathrm{Wu}, \mathrm{Y}$. Perfluorinated compounds in human blood around Bohai Sea, China. Chemosphere 2011, 85 (2), 156-162.

(43) Leitlinien zur vorläufigen Bewertung von PFC-Verunreinigungen in Wasser und Boden; Bayerisches Landesamt für Umwelt: 2015. http:// www.lfu.bayern.de/analytik_stoffe/loeschschaeume/doc/pfc_ bewertungsleitlinien_03_2013.pdff (accessed June 2, 2015).

(44) Perfluorooctanoate (APFO) and from their use in consumer articles. Evaluation of the risk reduction measures for potential restrictions on the manufacture, placing on the market and use of PFOA and APFO; RPS Advies B.V.: 2010. http://ec.europa.eu/enterprise/sectors/chemicals/ files/docs_studies/final_report_pfoa_pfos_en.pdf (accessed June 2, 2015).

(45) Wang, Z.; Cousins, I. T.; Scheringer, M.; Hungerbuehler, K. Hazard assessment of fluorinated alternatives to long-chain perfluoroalkyl acids (PFAAs) and their precursors: status quo, ongoing challenges and possible solutions. Environ. Int. 2015, 75, 172-179. 